\title{
Correlation between Vitamin D and HbAlc in Type 2 Diabetic Patients
}

\author{
Sudhir Chandra Jha ${ }^{\oplus 1}$, Himanshu Kumar ${ }^{\circledR 2}$, Syed Yousuf Faisal ${ }^{\circledR 3}$ \\ ${ }^{1}$ Associate Professor, Department of Medicine, Darbhanga Medical College and Hospital, Darbhanga, Bihar, India, ${ }^{2}$ Post Graduate Resident, Department of Medicine, \\ Darbhanga Medical College and Hospital, Darbhanga, Bihar, India, ${ }^{3}$ Senior Resident, Department of Medicine, Darbhanga Medical College and Hospital, Darbhanga, \\ Bihar, India.
}

\section{Abstract}

Background: Diabetes is a metabolic disorder that can affect nearly every organ system in the body. Recently, Vitamin D3 was given some importance worldwide in the pathogenesis of diabetes. The extraskeletal effects of Vitamin D3 have attracted considerable interest. The identification of 1,25-Dihydroxyvitamin D3 and 1-Alpha-Hydroylase expression in pancreatic Beta cells, in cells of the immune system,and in various other tissues besides the bone system, supports the role of Vitamin D3 in the pathogenesis of type 2 diabetes. Vitamin D3 deficiency appears to be related to development of diabetes mellitus type 2 and metabolic syndrome. The aim of the study is to find out whether this correlation between vitamin D and Diabetes is present or not. Mainly in this study we have tried to correlate Vitamin D with HbA1C levels in patients with Type 2 diabetes mellitus. Subjects and Methods: The present one and half years, cross sectional study was carried out in department of medicine, Darbhanga Medical College and Hospital, Darbhanga, Bihar from March - 2018 to September - 2019. A total of 125 patients with type 2 Diabetes Mellitus were studied. The estimation of vitamin D was done. Using Siemens, ADVIA centraurVit D assay a one pass 18 minute antibody competitive immunassay. Results: Maximum no. of cases was in the age group of 51 to 60 that is 40 patients (32\%). The mean age of studied population was $60.22+-11.65$ years. Out of 125 patients $77(61.6 \%)$ were males and 48 patients $(38.4 \%)$ were females, with a ratio of male to female of 1.60:1. In 104 patients (83.2\%), the level of vitamin D were below normal, in 11 patients (8.8\%) the levels insufficient and in remaining 10 patients, the levels were either normal or more than normal. Conclusion: There was an inverse association between Vitamin D and HbA1C in patients with type -2 Diabetes Mellitus. Lower Vitamin D levels are associated with poor glycemic control. That means in case of low Vitamin D the study reveals high HbA1C. Vitamin D deficiency is prevalent in Diabetes mellitus Type 2 so by supplementation of vitamin D we can improve glycemic controls in patients of Diabetes mellitus Type 2. By improving glycemic control, we can reduce the complication of Diabetes.

Keywords: HbA1c, Type 2 Diabetes Mellitus, Vitamin D

Corresponding Author: Himanshu Kumar, Post Graduate Resident, Department of Medicine, Darbhanga Medical College and Hospital, Darbhanga, Bihar, India.

E-mail:mikku@gmail.com

Received: 11 January 2020

Revised: 4 February 2020

Accepted: 16 February 2020

Published: 18 May 2020

\section{Introduction}

Type 2 Diabetes (T2DM) is a worldwide pandemic and India being capital for it.Thirty Five years ago, the prevalence of Diabetes in India based on the Indian Council of Medical Research (ICMR) multicentricsurve was around 2\% in urban India and $1 \%$ in rural India. ${ }^{[1,2]}$ In just Decades, there prevalence rates have shot up to $12-16 \%$ in urban India, ${ }^{[3]}$ to $8 \%$ in rural India,in adults over 20 years of age.This represents a 600- $800 \%$ increase in prevalence rates of Diabetes something which is unparallel in any western nation. That is why, India is now referred as "Diabetic Capital "of the world. Recently Vit-D3 was given some importance worldwide in the pathogenesis of Diabetes. ${ }^{[3]}$ One of the most important hallmark of T2DM is the occurance of low grade inflammation as a result of an increase in circulating cytokines TNF-alpha and IL-6, which contributes in the development of insulin resistance,particularly in the muscles and adipose tissue. ${ }^{[4]}$ Vitamin D3 being a potent immunosuppressant, tends to down regulate the transcription of various pro-inflammatory cytokine genes, like interleukin-2 interleukin-12 and Tumour necrosis factor-alpha. ${ }^{[5,6]}$ It also has a protective role on beta cell mass and prevents it from apoptosis as the beta cell apoptosis would lead to various pathological manifestation like excessive cytokines (TNF-alpha,IL-6) production, glucotoxicity, lipotoxicity which are the major features among the patient with T2DM.7 The discovery of vitamin D receptors for, 1-alpha,25 Dihydroxyvitamin D 3(1,25(OH)2D3), the acti- 
vated form of vitamin-D, in tissues with no direct role in calcium and bone metabolism (eg. Pancreatic Beta cells and cells of the immune system ) has broadened our view of the physiological role of vitamin $-\mathrm{D} .{ }^{[7,8]}$ This novel risk factor in the development of Diabetes has recently gained attention and remains unexplored.The study from Vacek et al. (2012), ${ }^{[9]}$ found an important role of vitamin D in cardiovascular health and Diabetes and found that vitamin D deficiency was related to reduced survival.The role vitamin-D in T2DM suggested by Pittas et al. ${ }^{[1]}$ in his study, documenting that insulin sensitivity is improved by as much as $60 \%$ when levels of 25-Hydroxy vitamin-D3 are increased from 25 to $75 \mathrm{nmol} / \mathrm{L}$ and this was also quoted by few of the studies done in India.Vitamin-D helps in insulin secretion by stimulating Beta cells secretions or it may facilitate the conversion of pro-insulin to insulin.Vitamin-D improves sensitivity and promotes beta -cells survival by modulating the effects of cytokines. Therefore, vitamin D deficiency may be implicated in pathogenesis of T2DM. However, the role of vitamin $\mathrm{D}$ in T2DM remains unexplored, so far, very few studies have explored the role of vitamin-D and Type $2 \mathrm{DM}$ in India. Hence the present study was undertaken to estimate the levels of vitamin D in patients with T2DM and correlate levels of vitamin-D with glycemic status of Diabetes Mellitus.

\section{Subjects and Methods}

The present cross -sectional study was conducted in the Department of Medicine, Darbhanga Medical College, Darbhanga from February -2018 to July -2019, on newly detected and known patients with T2DM. A total of 125 patients with T2DM were included in our study. The study was carried out after obtaining the clearance from the institutional ethical committee and getting the informed consent from all the patients.

\section{Inclusion criteria}

- Patient with T2DM,

- Age more than 18 years.

\section{Exclusion criteria}

- Age less than 18 years,

- Patient with chronic renal failure which corresponds to chronic kidney disease stages $3-5$ (GFR $<60 \mathrm{ml} / \mathrm{min}$ per 1.73 m-sq.)

All routine and relevent investigation were done like complete blood count, fasting and post prandial Blood sugar, HbA1C, routine exam urine, renal function test, lipid profile, 25 hydroxy vitamin D level. Anthropometric measurement was taken on Standing Height in meter, Weight in kg, Hip and Waist circumference in $\mathrm{cms}$ and Body Mass Index were calculated by using formula weight / height in meter square. Individuals were divided into three groups according to their plasma vitamin $-D$ levels:-

Group 1: Deficiency $(<20 \mathrm{mg} / \mathrm{ml})$

Group 2: Insufficiency $(20-30 \mathrm{mg} / \mathrm{ml})$

Group 3: Normal ( $>30 \mathrm{mg} / \mathrm{ml}$ )

The same individuals were regrouped on the basis of $\mathrm{HbA1C}$ level. As per ADA guidelines the target in diabetic patients is to achieve an HbA1C of less than 7. So, on the basis of this data we classified the subjects in following 3 groups.

Group A: Less than $7 \%$

Group B: 7-8 \%

Group C: More than $8 \%$

\section{Statistical Analysis}

The data obtained was coded and entered into Microsoft Excel Worksheet. The categorical Data was expressed as Rates, Ratio Proportions and comparison was done using chi-square test. The continuous data was expressed as mean +- standard deviation (SD) and comparison was done by two sample ' $t$ ' test with unequal variance. A probability value ('p' value) of less than or equal to 0.05 was considered as statistically significant.

\section{Results}

The present cross- sectional study titled "A study on the association between $\mathrm{HbA1C}$ and vitamin $\mathrm{D}$ in Type 2 Diabetes Mellitus was carried out in Department of Medicine, Darbhanga Medical College and Hospital Darbhanga, Bihar. A total 125 patients were studied. The findings /observations and final results are tabulated below.

\section{Age Distribution}

Patients age ranged from 39 to 85 years, maximum number of cases were in the age group of 51 to 60 that is 40 patients (32\%), between 61 to 70 years 36 patients $(28.8 \%)$ and between 41 to 50 years and 71 to 80 years 19 patients (15.2\%) in each group. The mean age of study population was $60.22 \pm$ 11.65 years.

\section{Sex Distribution}

Out of 100 patients $77(61.6 \%)$ were males and 48 patients $(38.4 \%)$ were Females, accounting a ratio of male to female 1.60:1.

Inference: Male preponderance was observed.

\section{Duration of diabetes}

In the present study, we observed in $26.9 \%$ patients the duration of diabetes Was 6 to 10years. In 41.6 of patients the duration of diabetes was either less than 5 years or upto 5 years. In $16 \%$ of patients the duration of diabetes was $>15$ years. The mean duration of diabetes was $7.4 \pm 5.44$ years. 


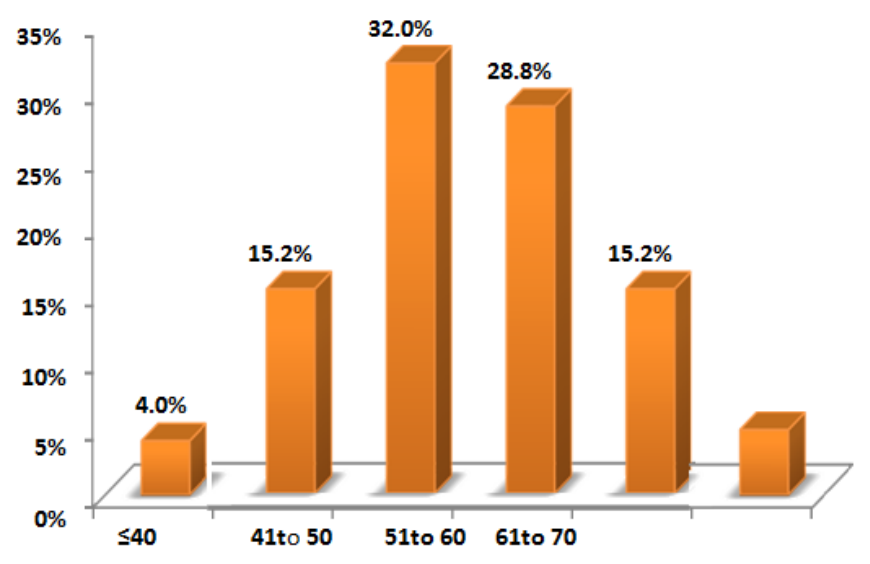

Figure 1: Age Distribution

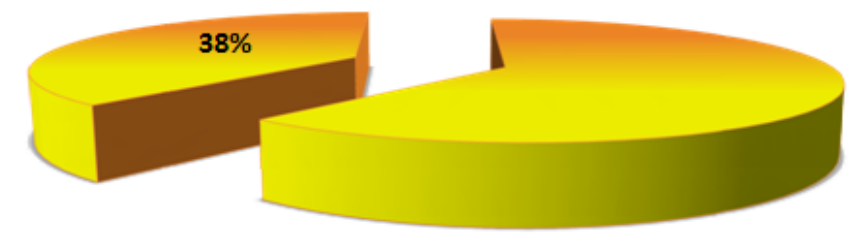

Figure 2: Sex Distribution

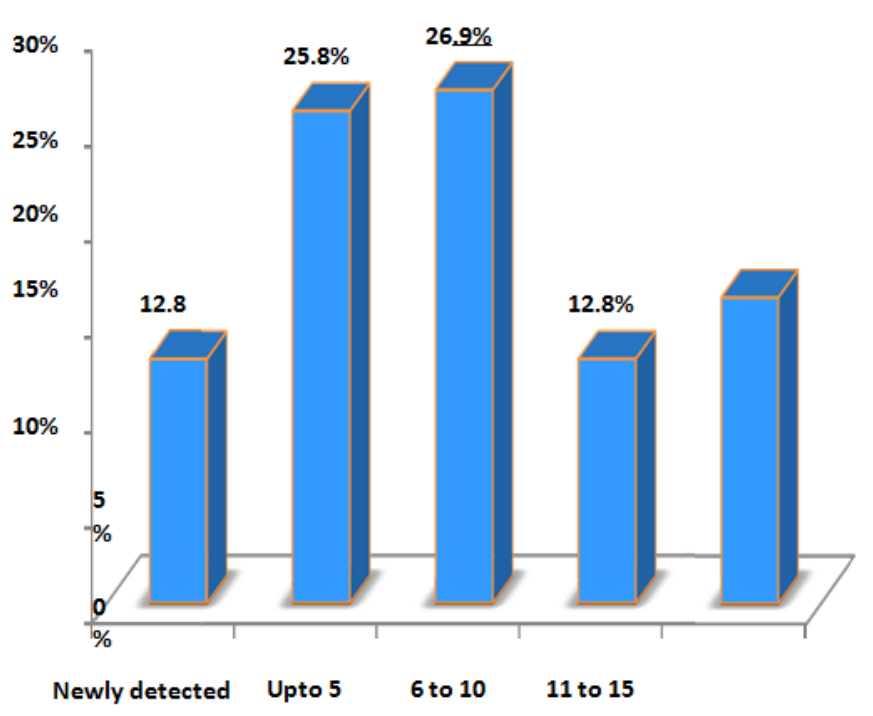

Figure 3: Duration of Diabetes

\section{Mode of treatment}

We observed 70 patients $(56 \%)$ were on oral hypoglycemic agents, 30 patients $(24 \%)$ were on insulin preparations, 16 patients $(12.8 \%)$ were newly detected and 9 patients $(7.2 \%)$ were on combination of insulin and oral hypoglycemic agents.

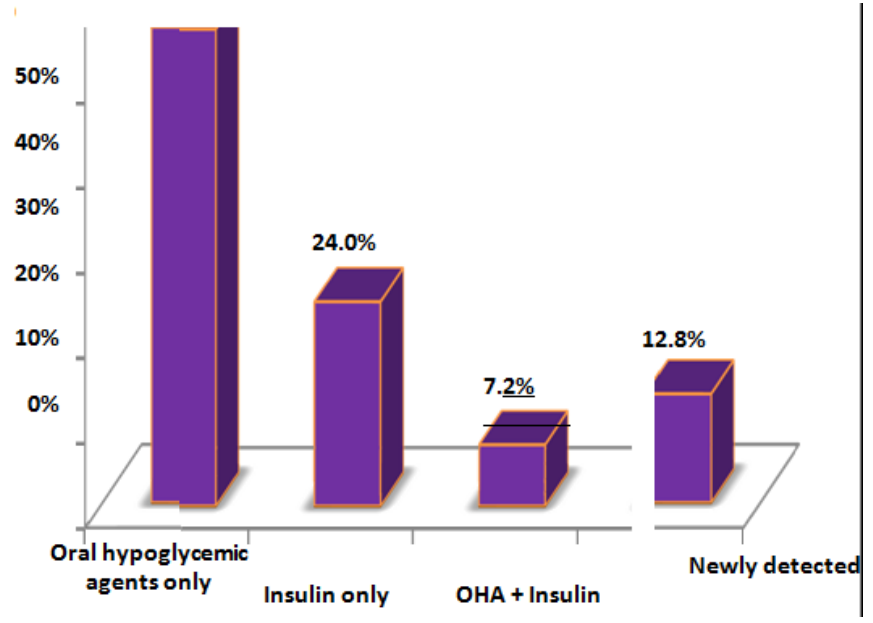

\section{Figure 4: Mode of Treatment}

\section{Habits}

In 15 patients $(12 \%)$ history of alcohol consumption, 9 patients $(7.2 \%)$ history of tobacco smoking and in 6 patients $(4.8 \%)$ history of smoking and alcohol consumption was obtained.

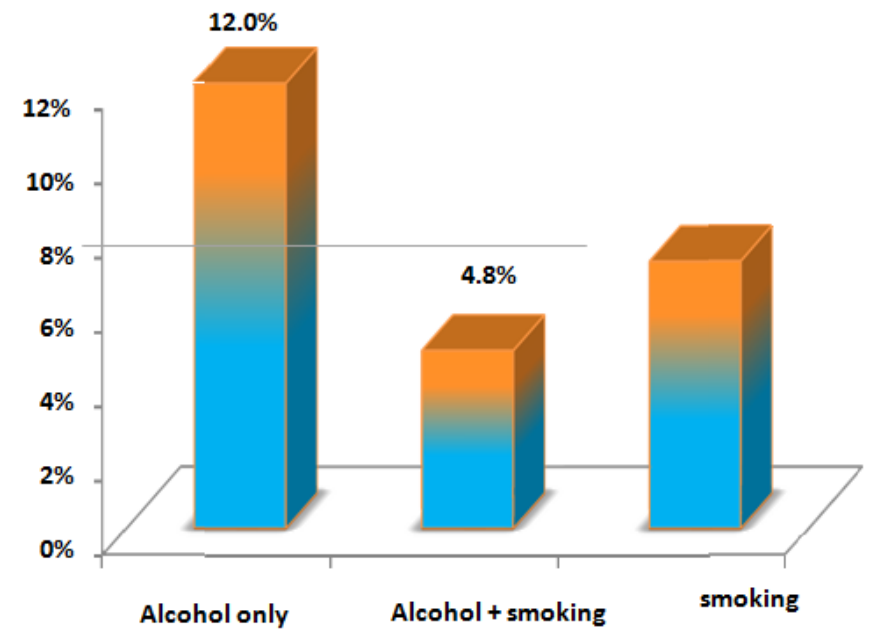

\section{Figure 5: Habit.}

\section{Body Mass Index}

We observed in 94 patients (75.6\%) BMI of 25 to 29.99 , in 17patients (13.6\%) BMI of 23 to 24.99, In 12 patients (9.6\%) 
BMI was $>30$ and in only 2 patients $(1.6 \%)$ BMI was 18.5 to 22.99. The mean BMI was $26.95 \pm 3.15$.

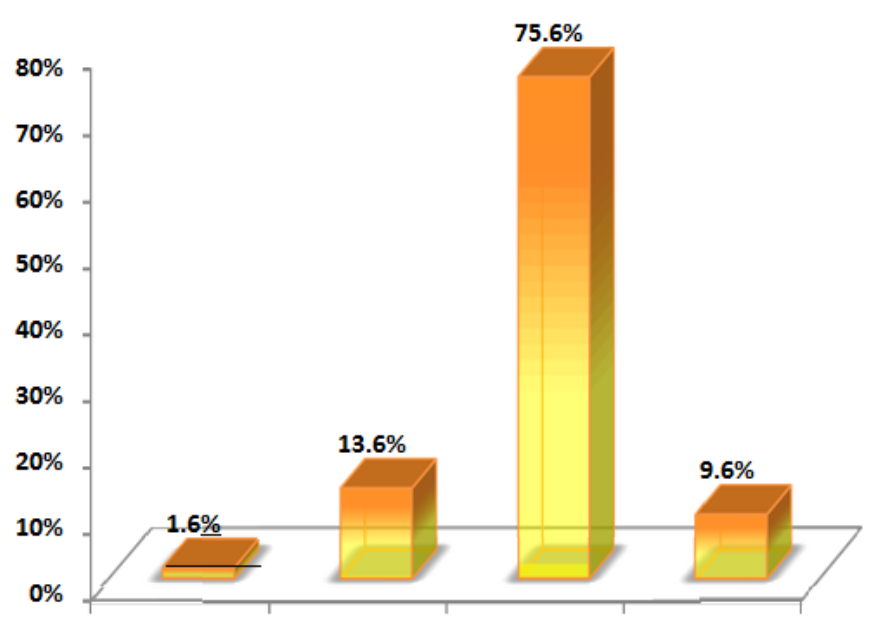

18.5to 22.99 23.0to 24.9925 .0 to 29.9930 ormore

\section{Figure 6: Body Mass Index}

\section{Fasting blood sugar (FBS)}

Most of our patients who presented had fasting glucose abnormality (98\%) except 4 patients $(3.2 \%)$.

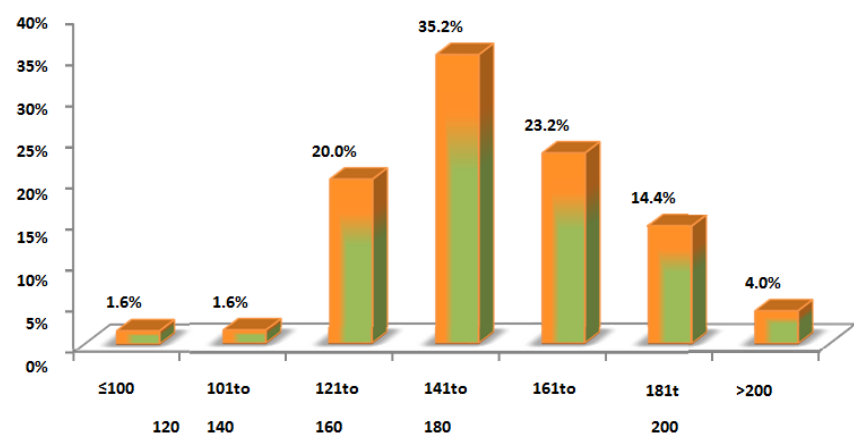

\section{Figure 7: Fasting Blood Sugar}

\section{Post prandial blood sugar (PPBS)}

Almost all our patients had post-prandial glucose abnormality (98.4\%). 2 patients (1.6\%) had post-prandial blood sugar $<200$ $\mathrm{mg} \%$.

\section{HbA1c levels}

In our present study 90 patients $(72 \%)$ had HbAlc of more than $8.0 \%, 23$ patients $(18.4 \%$ ) had HbAlc between 7.1 to $8.0 \%$ randomly 12 patients $(9.6 \%$ ) were between 6.5 to $7.0 \%$. The mean HbA1c level was $8.26 \pm 0.78$.

\section{Vitamin D level}

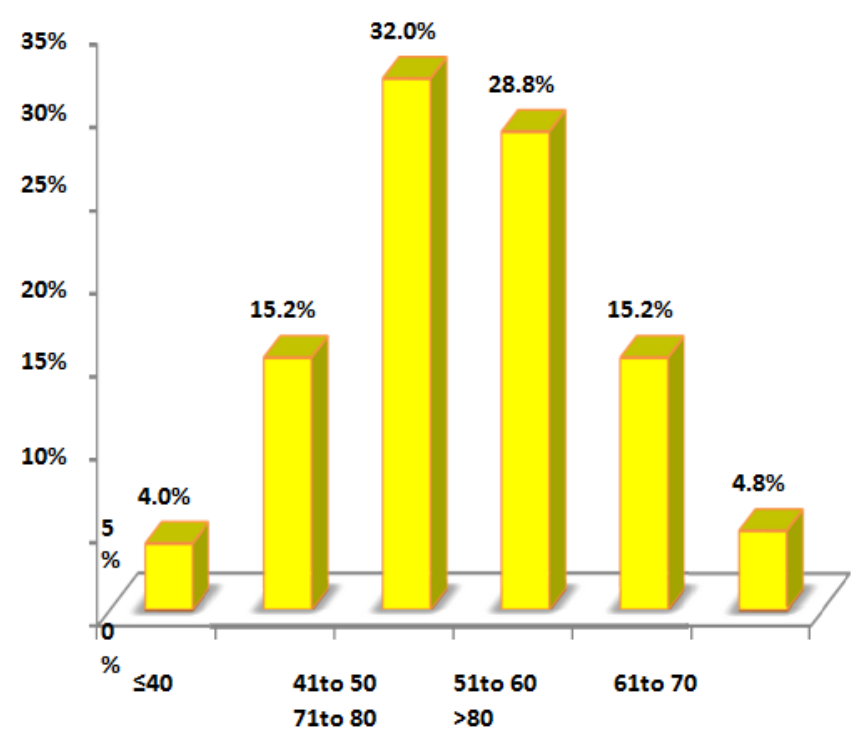

\section{Figure 8: Post Prandial Blood Sugar}

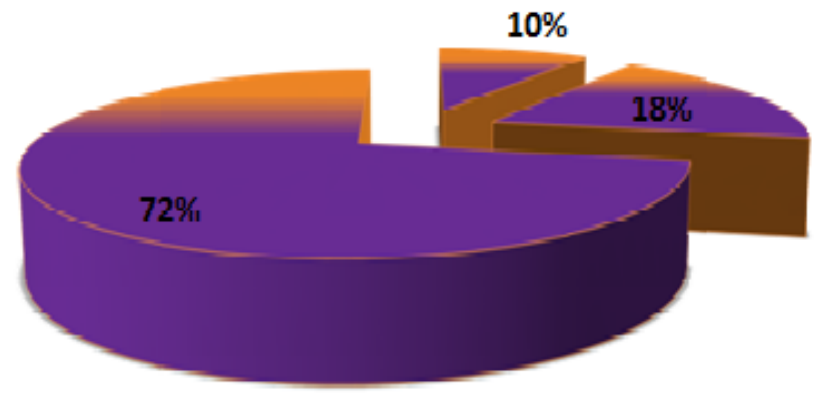

6.5-7.0 $\quad 7.1-8.0$

$>8.0$

We observed in 104 patients (83.2\%) the level of VitaminD were below normal, in 11 patients $(8.8 \%)$ the levels were insufficient and in remaining 10 patients $(8 \%)$ the levels were either normal or more than normal.

\section{Correlation of Vitamin D levels with HbA1c}

When Vitamin D levels were correlated with HbA1c, 104 patients had low levels of Vitamin D (7 patients had HbA1c between 6.5 - 7.0\%, in 15 patients HbA1c was $7.1-8.0 \%$ and in remaining 82 patients $\mathrm{HbAlc}$ was $>8.0 \%) .11$ patients had insufficient Vitamin D levels ( in 3 patients HbA1c was $6.5-7.0 \%$ in 4 patients $7.1-8.0 \%$ and in 4 patients it was 


\section{Graph - 14. Vitamin D level}

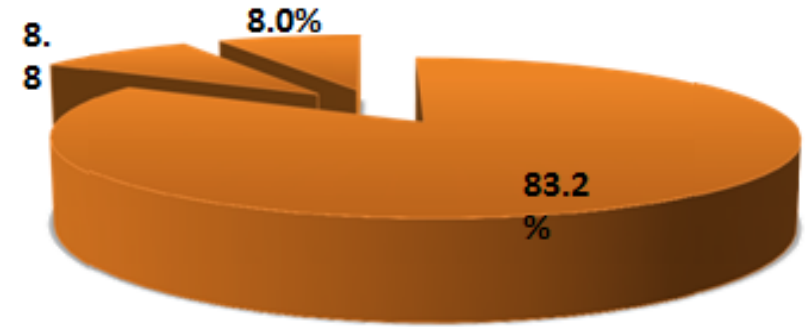

Figure 10: 10: Vitamin D level

$>8.0 \%) .10$ patients had normal Vitamin D levels (2 patients had HbAlc between $6.5-7.0 \%$, in 4 patients HbAlc was 7.1 $8.0 \%$ and $4 \mathrm{had}>8.0 \%$ ). We obtained a p-value of 0.005 when we correlated Vitamin D levels with HbAlc. This p value is significant.

\section{Discussion}

Management of type 2 diabetes mellitus is a challenge for health care workers, patients and their families. Current management standards focus on optimizing glycaemic control to reduce risk of long term complications. The main aim of our investigation was to clarify,whether there exists association between vitamin $\mathrm{D}$ levels and glycatedhemoglobin in patients of type 2 diabetes mellitus.In the present study of 125 patients with type 2 diabetes mellitus, we observed the levels of vitamin $\mathrm{D}$ and compared it to various factors. In this cross sectional study, we found an inverse association between vitamin D levels and $\mathrm{HbAlc}$.In our study the patients ranged from 39 to 85 years. 61 patients were in the age group of $>60$ years. 53 patients had low levels of vitamin D, 2 had insufficient levels and 6 had either normal or more than normal levels. We observed that levels of vitamin-D were low with increasing age $(\mathrm{p}=0.147$; insignificant).This observation is similar to a study by Baynes KCR et al ${ }^{[10]}$ ( $p=<0.05$; significant). Maybe this finding in their study is because of adjusting various confounding factors and following up of these patients for nearly 30 years. One study by Dalgard $C$ et al, ${ }^{[11]}$ observed low levels of vitamin-D with increasing age. The reason for this could be the synthesis of vitamin D decreases with increasing age due to reduced concentration of 7-dehydrocholesterol in the skin and may be due to reduced absorption of oral vitamin-D. Taking gender into consideration, no significant association was found ( $\mathrm{p}=0.344$; insignificant) in our study. Same observation was made by Ford ES et al. ${ }^{[12]}$ In our study, the duration of diabetes varied from 0 to $>15$ yrs. We did not find any association between Vitamin-D levels and duration of diabetes. This is in sharp contrast to study by Braun TR et al, ${ }^{[13]}$ who observed lower Vitamin-D in patients with longer duration of diabetes. Some of our patients were on treatment either with oral hypoglycemic agents (56\%), Insulin preparations $(30 \%)$, or a combination of oral hypoglycemic drugs and insulin (7.2\%) and $12.8 \%$ were newly detected diabetics. All of these patients when presented had either fasting blood sugar or post prandial blood sugar abnormality reflecting poor diabetic status. Most of our patients were having low or insufficient levels of vitamin- D (except 10 patients who had either normal or more than normal). Same conclusion was drawn by Braun TR et al. ${ }^{[13]}$ This issue needs further evaluation by comparing the diabetic patients with healthy non-diabetic individuals. We obtained in 24 patients history of alcohol consumption, history of smoking in 20 and 14 patients had history of smoking as well as alcohol consumption. Whether these confounding factors have effect on Vitamin-D levels is not clear. Similar observation was found by Braun TR et al, ${ }^{[13]}$ Study by Baynes KCR et al, ${ }^{[10]}$ found no correlation with alcohol consumption and smoking. When the levels of vitamin -D were compared with BMI, the vitamin - D levels were less in patient s with BMI above 23.0, however $\mathrm{p}$ value was not statistically significant $(\mathrm{p}=0.423)$. In a study by Braun TR et al, ${ }^{[13]}$ correlation between BMI and low levels of vitamin- D levels had a significant value $(\mathrm{p}<0.0001)$ This difference could be because of small sample size(125 patients) in our study compared to their sample size of 887 patients.In the study of Baynes KCR et al, ${ }^{[10]}$ there was no correlation with BMI. When vitamin D levels were compared with fasting blood sugar, most of patients with fasting glucose abnormality had either low levels of vitamin$\mathrm{D}$ or insufficient levels $(\mathrm{p}=0.280$; insignificant). Braun TE et ${ }^{2},{ }^{[13]}$ in their study (sample size 887 cases ), observed low levels of vitamin - D are associated with fasting blood glucose abnormality ( $\mathrm{p}=0.022$; significant) .Similarly study done by Shanthi $\mathrm{B}$ et al, ${ }^{[14]}$ (sample size 50 patients) found a negative correlation of vitamin $\mathrm{D}$ with fasting glucose abnormality.(P- 0.534 , ; insignificant). Study by Lu L et al, ${ }^{[15]}$ and Kotwal SK et al, ${ }^{[16]}$ found low levels of vitamin D in patients with increasing fasting blood sugars. When vitamin -D levels were compared with post prandial blood sugar, almost all of our patients with post prandial blood sugar abnormality had either low or insufficient levels( $\mathrm{p}=0.396$; insignificant). Same was observed by Shanthi B et al, ${ }^{[14]}$ $(\mathrm{p}=0.511$; insignificant) When correlated with $\mathrm{HbAlc}$ the vitamin-D levels were definitely effected with $\mathrm{HbA1c}$ of $6.5 \%$ and above. In 10 patients normal levels of vitamin $\mathrm{D}$ was observedinspite having HbAlc abnormality, $\mathrm{p}$ value being significant $(\mathrm{p}=0.005)$ Similar observation was made by Dalgard $\mathrm{C}$ et al, ${ }^{[11]}$ ( $\mathrm{p}=0.01$; significant). In a study done by $\mathrm{Lu}$ $\mathrm{L}$ et al, ${ }^{[15]}$ they found an inverse association between Vitamin - D levels and HbA1c, p value was significant $(\mathrm{p}=<0.0001)$. When the available data was analyzed both quantitatively and 
qualitatively to find out correlation of levels of vitamin - D in patients of type 2 diabetes mellitus we found a significant correlation when compared with $\mathrm{HbA} 1 \mathrm{c}$, cholesterol and low density lipoprotein ( $\mathrm{p}$ value being significant ). Other variables like age gender, duration of diabetes, body mass index, fasting blood sugar and postprandial blood sugar. To overcome this bias with confounding factors and co - morbid conditions, may be large sample size is required.And also comparison of diabetic individuals with non diabetic healthy individuals is essential. To find out the true correlation of vitamin D levels with these variables.

\section{Conclusion}

There was an inverse association between Vitamin D levels and $\mathrm{HbAlc}$ in patients with type 2 diabetes mellitus. In the present study of 125 patients with type 2 diabetes mellitus we found that lower vitamin $\mathrm{D}$ levels were associated with poor glycemic control. When correlated with other variables like age, gender, duration of diabetes, body mass index, fasting blood sugar, post prandial blood sugar we found no significant correlation ( $\mathrm{p}$ - value being statistically insignificant). Further studies to compare patients with type 2 diabetes mellitus and non diabetic healthy individuals may be necessary to know the relationship between Vitamin - D levels and other variables. There is evidence that vitamin D deficiency leads to glucose intolerance and predisposes to type 2 diabetes mellitus. Despite observational studies showing strong association between Vitamin D deficiency and diabetes mellitus, randomized clinical trials with vitamin D supplementation are of short duration, with small number of patients, and small doses if vitamin D supplementation, thereby not permitting any definitive conclusions. Questions persist about the optimal level of vitamin D to prevent the risk of developing diabetes mellitus. However, large long - term clinical trials are needed to clarify these issues. Vitamin D is inexpensive and should a trial confirm its benefit in prevention of diabetes, it will have a major impact on public health.

\section{References}

1. Parker J, Hashmi O, Dutton D, Mavrodaris A, Stranges S, Kandala NB, et al. Levels of vitamin D and cardiometabolic disorders: Systematic review and meta-analysis. Maturitas. 2010;65(3):225-236. Available from: https://dx.doi.org/10. 1016/j.maturitas.2009.12.013.

2. Tripathybb, Chandaliahb. Comparative Study of the Prevalence of Type-2 Diabetes Mellitus in Various Demographic Regions of Andhra Pradesh, India: a Population based Study. Int J MCH AIDS. 2016;5(2):103-111.

3. Stivelman E, Retnakaran R. Role of vitamin D in the pathophysiology and treatment of type 2 diabetes. Curr Diabetes Rev. 2012;8(1):42-47. Available from: https://dx.doi. org/10.2174/157339912798829179.

4. Hotamisligil GS, Arner P, Caro JF, Atkinson RL, Spiegelman BM. Increased adipose tissue expression of tumor necrosis factor-alpha in human obesity and insulin resistance. J Clin Invest. 1995;95(5):2409-2415. Available from: https://dx.doi. org/10.1172/jci117936.

5. Schleithoff SS, Zittermann A, Tenderich G, Berthold HK, Stehle P, Koerfer R. Vitamin D supplementation improves cytokine profiles in patients with congestive heart failure: a double-blind, randomized, placebo-controlled trial. Am J Clin Nutr. 2006;83(4):754-759. Available from: https://dx.doi.org/ 10.1093/ajcn/83.4.754.

6. Pittas AG, Dawson-Hughes B. Vitamin D and diabetes. J Steroid Biochem Mol Biol. 2010;121(1-2):425-429. Available from: https://dx.doi.org/10.1016/j.jsbmb.2010.03.042.

7. Kayaniyil S, Vieth R, Retnakaran R, Knight JA, Qi Y, Gerstein $\mathrm{HC}$, et al. Association of Vitamin D With Insulin Resistance and -Cell Dysfunction in Subjects at Risk for Type 2 Diabetes. Diabetes Care. 2010;33(6):1379-1381. Available from: https: //dx.doi.org/10.2337/dc09-2321.

8. Chiu KC, Chu A, Go VLW, Saad MF. Hypovitaminosis D is associated with insulin resistance and $\beta$ cell dysfunction. Am J Clin Nutr. 2004;79:820-825. Available from: https://dx.doi. org/10.1093/ajcn/79.5.820.

9. Vacek JL, Vanga SR, Good M, Lai SM, Lakkireddy D, Howard PA. Vitamin D Deficiency and Supplementation and Relation to Cardiovascular Health. Am J Cardiol. 2012;109(3):359-363. Available from: https://dx.doi.org/10.1016/j.amjcard.2011.09. 020.

10. Baynes KCR, Boucher BJ, Feskens EJM, Kromhout D. Vitamin D, glucose tolerance and insulinaemia in elderly men. Diabetologia. 1997;40(3):344-347. Available from: https://dx. doi.org/10.1007/s001250050685.

11. Dalgard C, Petersen MS, Weihe P, Grandjean P. Vitamin D Status in Relation to Glucose Metabolism and Type 2 Diabetes in Septuagenarians. Diabetes Care. 2011;34(6):1284-1288. Available from: https://dx.doi.org/10.2337/dc10-2084.

12. Ford ES, Ajani UA, Mcguire LC, Liu S. Concentration of serum vitamin $\mathrm{D}$ and metabolic syndrome among U.S adults. Diabetes Care. 2005;28(5):1228-1258.

13. Braun TR, Been LF, Blackett PR, Sangheria DK. Vitamin D deficiency and cardiometabolic risk in north Indian community with highly prevelant Type 2 Diabetes. J Diabetes Metab. 2012;3:100213-100213.

14. Shanthi B, Revathy C, Majulidevi AJ, Parameshwari PJ, Stephan T. Serum $25(\mathrm{OH}) \mathrm{D}$ and type 2 diabetes mellitus. J Clin Diag Res. 2012;6(5):774-780.

15. Lu L, Yu Z, Pan A, Hu FB, Franco OH, Li H, et al. Plasma 25-Hydroxyvitamin D Concentration and Metabolic Syndrome Among Middle-Aged and Elderly Chinese Individuals. Diabetes Care. 2009;32(7):1278-1283. Available from: https://dx. doi.org/10.2337/dc09-0209.

16. Laway BA, Kotwal SK, Shah ZA. Pattern of 25 hydroxy vitamin D status in North Indian people with newly detected type 2 diabetes: A prospective case control study. Indian J Endocrinol Metab. 2014;18(5):726-730. Available from: https: //dx.doi.org/10.4103/2230-8210.139242. 
Copyright: (C) the author(s), 2020. It is an open-access article distributed under the terms of the Creative Commons Attribution License (CC BY 4.0), which permits authors to retain ownership of the copyright for their content, and allow anyone to download, reuse, reprint, modify, distribute and/or copy the content as long as the original authors and source are cited.

How to cite this article: Jha SC, Kumar H, Faisal SY. Correlation between Vitamin D and HbA1c in Type 2 Diabetic Patients. Acad. J Med. 2020;3(1):4-10.

DOI: dx.doi.org/10.47008/ajm.2020.3.1.2

Source of Support: Nil, Conflict of Interest: None declared. 